\title{
Dexmedetomidine-induced hemodynamic instability in patients undergoing orthopedic upper limb surgery under brachial plexus block: a retrospective study
}

\author{
A Ram Doo ${ }^{1,2}$, Hyungseok Lee ${ }^{1}$, Seon Ju Baek ${ }^{1}$ and Jeongwoo Lee ${ }^{1,2^{*}}$
}

\begin{abstract}
Background: Hemodynamic instability is a frequent adverse effect following administration of dexmedetomidine (DMED). In this study, we evaluated the incidence of DMED-induced hemodynamic instability and its predictive factors in clinical regional anesthesia practice.
\end{abstract}

Methods: One hundred sixteen patients who underwent orthopedic upper limb surgery under brachial plexus block with intravenous DMED administration were retrospectively identified. The primary outcome was the incidence of DMED-induced hemodynamic instability. The participants were allocated to a stable or unstable group by their hemodynamic instability status. Patients' characteristics were compared between the groups. The relationship between the potential risk factors and development of DMED-induced hemodynamic instability was analyzed with a logistic regression model.

Results: DMED-induced hemodynamic instability was observed in $14.7 \%$ of patients (17/116). The unstable group had more women than the stable group $(76.5 \% \mathrm{vs.} 39.4 \%, P=0.010)$. When patients were classified into four subgroup according to body mass index (underweight, normal weight, overweight, and obesity), there was significant difference in the composition of the subgroups in the two groups $(P=0.008)$. In univariate analysis, female sex, obesity, and pre-existing hypertension were significant predictors of DMED-induced hemodynamic instability. Multivariate analysis demonstrated that female sex (adjusted $\mathrm{OR} 3.86, \mathrm{Cl} 1.09 ; 13.59, P=0.036$ ) and obesity (adjusted $\mathrm{OR} 6.41, \mathrm{Cl} 1.22 ; 33.57$, $P=0.028$ ) were independent predictors of DMED-induced hemodynamic instability.

Conclusions: Female and obese patients are more likely to have hemodynamic instability following intravenous DMED administration in clinical regional anesthesia practice. This study suggests that DMED dose may be diminished to prevent hypotensive risk in these populations.

Trial registration: This article was retrospectively registered at WHO clinical trial registry platform (Trial number: KCT0005977).

Keywords: Brachial plexus block, Dexmedetomidine, Procedural sedation, Regional anesthesia, Hypotension, Obesity, Orthopedic, Perioperative

\footnotetext{
*Correspondence: jw88lee@gmail.com

${ }^{1}$ Department of Anesthesiology and Pain Medicine, Jeonbuk National

University Hospital and Medical School, 20 Geonji-ro, Deokjin-gu, Jeonju 54907, Jeollabuk-do, South Korea

Full list of author information is available at the end of the article
}

\section{Background}

Regional anesthesia increasingly expands its role in perioperative care. The clinical benefits of regional anesthesia include better postoperative analgesia, preserved 
consciousness during surgery, and possibly lower incidence of postoperative delirium or cognitive dysfunction. However, in clinical practice, because awake patients often complain of anxiety or discomfort during surgical procedures regardless of the type of regional anesthesia provided, various sedatives and additional analgesics are commonly used. Dexmedetomidine (DMED), a highly selective $\alpha 2$-adrenergic agonist, is the most preferred sedative because of its advantages. One of these is conscious sedation with minimal respiratory depression, enabling the patients to be more cooperative during the intervention. DMED also manifests sympatholytic, sedative, hypnotic, amnesic, and analgesic properties. Consequently, DMED is increasingly used for procedural sedation during intervention, sedation in intensive care patients with mechanical ventilation, and as an adjuvant in balanced anesthesia. Particularly, the benefits of DMED, when combined with regional anesthesia, includes increasing the regional anesthesia quality, prolonging postoperative analgesia, and endowing an opioid-sparing effect [1-3].

It is well known that the pharmacologic effect of DMED in the cardiovascular system includes the reduction of blood pressure and heart rate in a dose-dependent manner by activating the peripheral $\alpha 2$-adrenoreceptor [4-6]. Indeed, the occurrence of hemodynamic instability after DMED administration, including hypotension or bradycardia, has been reported in several investigations. The reported incidence of hemodynamic instability in the intensive care units (ICU) ranges from 20.6-71\% [7-10]. Several risk factors for DMED-induced hemodynamic instability, including older age and lower baseline blood pressure, were suggested [9]. However, these studies were limited to ICU settings. To the best of our knowledge, there had been no well-designed study to evaluate DMED-induced hemodynamic instability in clinical regional anesthesia practice, even though patients often experience such events in clinical practice.

In this study, we retrospectively evaluated the development of hemodynamic instabilities such as hypotension and bradycardia in patients administered with intravenous DMED for sedation during orthopedic upper limb surgery under brachial plexus block (BPB). The study aimed to evaluate the incidence of DMED-induced hemodynamic instabilities and determine predictive factors for such instabilities during procedural sedation in regional anesthesia practice.

\section{Methods}

This retrospective study was approved by the Institutional Review Board of Jeonbuk National University Hospital, Jeonju, South Korea, and the need to obtain informed consent was waived based on the Good Clinical Practice regulations and guidelines. This manuscript adheres to the applicable STROBE guidelines. We retrospectively evaluated the medical records of 205 consecutive patients who underwent orthopedic upper limb surgery under BPB at our institution between March 2017 and February 2020. Inclusion criteria were as follows: age $\geq 18$ years, American Society of Anesthesiologists (ASA) physical status (PS) I-III, administered with intravenous DMED during the surgery. Among the 192 patients enrolled, we analyzed the data of 116 patients in this study. We excluded from the analysis the following patients: 1) Patients who were given an intravenous opioid-based patient-controlled analgesia device at the end of anesthesia $(n=67), 2)$ Patients who had severe hepatic or renal impairment $(n=3), 3)$ Emergent operation $(n=2), 4)$ Patients whose pre-anesthetic heart rate was less than 50 beats per minute (bpm) (baseline bradycardia; $n=1)$, and 5) Others $(n=3)$. Subject selection is presented as a flow diagram in Fig. 1.

The primary outcome was the incidence of DMEDinduced hemodynamic instability. The participants were classified into the stable or unstable groups based on their hemodynamic instability status. Secondary outcome included the patients' characteristics in each subgroup and the predictive risk factors associated with the development of DMED-induced hemodynamic instability. The patients' demographic data, including age, sex, height, weight, body mass index (BMI), and general medical condition, were collected by reviewing the medical charts. The presence of underlying diseases such as hypertension, cardiovascular disease, cerebrovascular disease, and diabetes mellitus was also recorded. The data related to the DMED usage during the operation included total drug administered and the infusion time. Concomitantly administered drugs, such as benzodiazepine or fentanyl, were also recorded. In all patients, hemodynamic parameters, including blood pressure and heart rate, were assessed at specific time points from the start of DMED infusion until the patients were discharged from the postanesthetic care unit (PACU).

The development of DMED-induced hemodynamic instability, such as hypotension or bradycardia, was identified. Hypotension was defined as systolic blood pressure (SBP) decreased by more than $30 \%$ of the baseline and/ or less than $90 \mathrm{mmHg}$, and bradycardia was defined as a heart rate of less than $50 \mathrm{bpm}$. To qualify as an event, SBP less than $90 \mathrm{mmHg}$ had to be recorded for at least two consecutive readings at 10 -min interval. The occurrence of these events was evaluated for five hours from the initiation of DMED infusion. Based on this evaluation, the participants were allocated to a stable or unstable group. The stable group included patients who did not experience hypotension and bradycardia, while the unstable group included patients presenting hemodynamic 


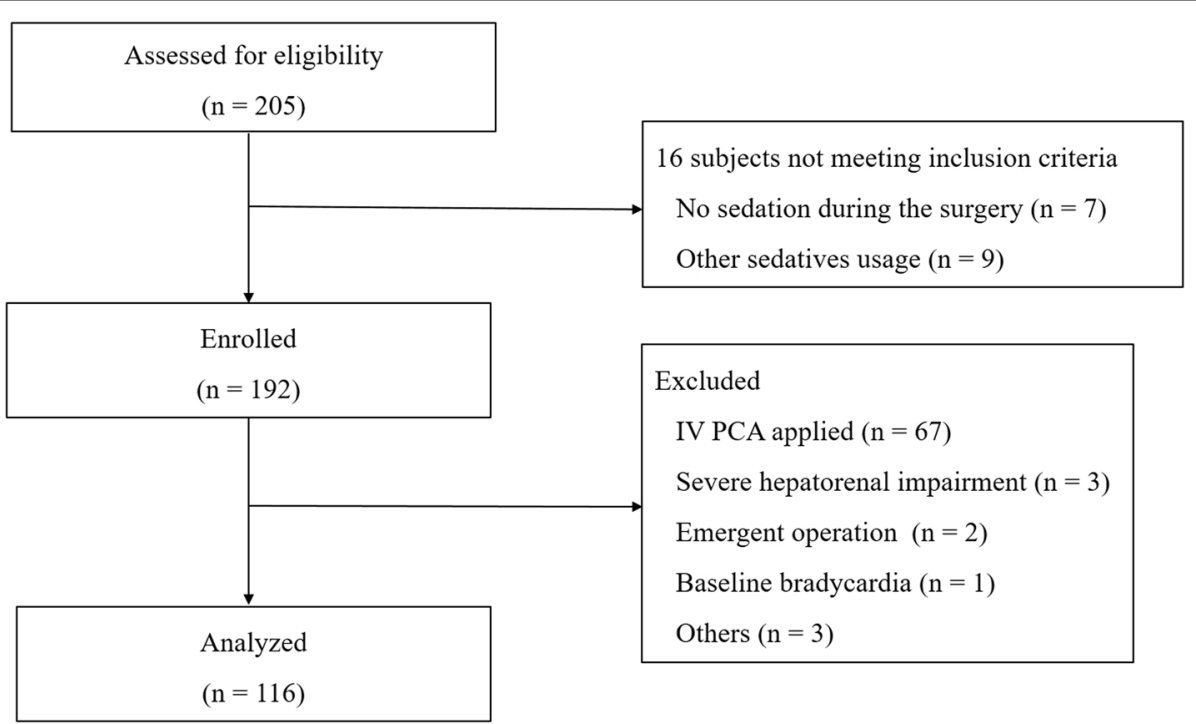

Fig. 1 Subject flow diagram

instability during the observation period. Meanwhile, transient hypertension following DMED loading was also identified. DMED-induced hypertension was defined as SBP increased by more than $30 \%$ of the baseline and/or more than $180 \mathrm{mmHg}$.

\section{Anesthesia management}

The ultrasound-guided supraclavicular BPB was performed in all patients enrolled in the present study. After identifying the brachial plexus using a $13-6 \mathrm{MHz}$ linear array transducer $\left(\mathrm{EDGE}^{\circledR}\right.$ ultrasound machine, Sonosite Inc., USA), a 25-gauge, $5 \mathrm{~cm}$ block needle was inserted toward the brachial plexus with a lateral to medical direction. Then, half the volume (16 ml) of $1.5 \%$ lidocaine with epinephrine $5 \mu \mathrm{g} / \mathrm{mL}$ was injected into the main neural cluster. The remaining half $(16 \mathrm{ml})$ was then injected into every satellite neural cluster by the previously described targeted intracluster injection method [11]. After a reliable motor and sensory block was confirmed, the infusion of DMED was initiated to achieve patients' sedation.

At our institution, when sedation is required during surgical procedure under regional anesthesia, the intravenous DMED infusion protocol follows the manufacturer's recommendation, which includes a standard initial loading dose of $1 \mu \mathrm{g} / \mathrm{kg}$ over ten minutes, and subsequent maintenance rate of $0.2-0.6 \mu \mathrm{g} / \mathrm{kg} / \mathrm{hr}$ until the end of the surgery. The maintenance rate may be titrated to achieve the target Modified Observer's Assessment of Alertness/ Sedation scale 3-4, representing moderate sedation. On this scale, $5=$ Responds readily to name spoken in a normal tone, $4=$ Lethargic response to name spoken in a normal tone, $3=$ Responds only after name is called loudly or repeatedly, $2=$ Responds only after mild prodding or shaking, $1=$ Responds only after painful trapezius squeeze, $0=$ No response after painful trapezius squeeze.

\section{Statistical analysis}

Statistical analysis was performed using IBM SPSS Statistics for Windows, version 25 (IBM Corp., Armonk, N.Y., USA). All descriptive data are expressed as mean (SD), median (interquartile range), and the number of patients (\%).

We first compared the clinical characteristics, including demographic data and the data related to DMED usage, between the stable and unstable groups. Twotailed independent-samples $t$-test or Mann-Whitney rank-sum $U$ test was used to analyze continuous variables after performing Shapiro-Wilk test. Chi-square test was used to compare categorical variables. Hemodynamic parameters, such as blood pressure and heart rate in both groups, were analyzed with two-way repeated measures analysis of variance (RM ANOVA), and posthoc analysis was performed by the Bonferroni correction procedure. Based on the statistical comparisons between the two groups, univariate logistic regression analysis was performed to identify potential risk factors for DMEDinduced hemodynamic instability, with the crude odds ratios (ORs) and their $95 \%$ confidence intervals (CIs). The statistically significant variables in the univariate analysis were integrated into a multivariate logistic regression model, and the adjusted ORs, 95\% CIs, and $p$ values were calculated for each variable. After the logistic regression model was established, further analysis included KaplanMeier survival method to estimate the cumulative 
incidence of DMED-induced hemodynamic instability and log-rank test to compare the survival curves between stratified patients' groups. Differences with a two-tailed $p$ value of $<0.05$ were considered statistically significant.

\section{Results}

The DMED-induced hemodynamic instability was observed in 17 of the 116 patients (14.7\%), of which 16 experienced hypotension, and one had bradycardia after DMED administration. These patients comprised the unstable group, while the rest $(n=99)$ formed the stable group. The patients' characteristics were compared between the stable and unstable groups (Table 1). The median ages in the two groups were comparable. In the unstable group, the proportion of females was significantly higher than in the stable group (76.5 vs. $39.4 \%$, $P=0.010$ ). Even though the BMI in the two groups was similar by two-tailed independent-samples $t$-test, when the patients of both group were classified into four subgroups by the BMI $\left(<18.5 \mathrm{~kg} / \mathrm{m}^{2}\right.$, underweight;
$18.5-24.9 \mathrm{~kg} / \mathrm{m}^{2}$, normal weight; $25.0-29.9 \mathrm{~kg} / \mathrm{m}^{2}$, overweight; $\geq 30.0 \mathrm{~kg} / \mathrm{m}^{2}$, obese), there was significant difference in the composition of the subgroups between the stable and unstable groups $(P=0.008$ by two-tailed Mann-Whitney rank-sum $U$ test). Among the patient's underlying medical conditions, hypertension was more prevalent in the unstable group than in the stable group ( 47.1 vs. $20.2 \%, P=0.037$ by Chi-square test). All patients with a history of hypertension, in both groups, were taking one or two anti-hypertensive medications, with no difference between the groups. The groups were also comparable in terms of the prevalence of coronary arterial disease and diabetes mellitus. Regardless of the development of DMED-induced hemodynamic instability, there was no difference between the groups in the DMED therapy characteristics, including the total consumption of the administered drug, total infusion time, or total drug administered per body weight (Table 2). The concomitant administration of other sedatives was also similar between the groups.

Table 1 Patient characteristics, stratified by hemodynamic instability status

\begin{tabular}{|c|c|c|c|}
\hline & $\begin{array}{l}\text { Stable group } \\
(n=99)\end{array}$ & $\begin{array}{l}\text { Unstable group } \\
(n=17)\end{array}$ & $P$ value \\
\hline Age (years) & $54.0(36.0-62.0)$ & $59.0(48.0-68.0)$ & 0.057 \\
\hline Female [n (\%)] & $39(39.4)$ & $13(76.5)$ & $0.010^{*}$ \\
\hline Body weight (kg) & $65.6(12.6)$ & $63.2(10.0)$ & 0.449 \\
\hline $\mathrm{BMI}\left(\mathrm{kg} / \mathrm{m}^{2}\right)$ & $24.3(3.6)$ & $26.1(4.0)$ & 0.058 \\
\hline \multicolumn{4}{|l|}{ Classification by BMI } \\
\hline Underweight [n (\%)] & $5(5.1)$ & 0 & $0.008^{\dagger}$ \\
\hline Normal weight [n (\%)] & $52(52.5)$ & $5(29.4)$ & \\
\hline Overweight [n (\%)] & $38(38.4)$ & $8(47.1)$ & \\
\hline Obesity [n (\%)] & $4(4.0)$ & $4(23.5)$ & \\
\hline \multicolumn{4}{|l|}{ Underlying disease [n (\%)] } \\
\hline Hypertension & $20(20.2)$ & $8(47.1)$ & $0.037^{*}$ \\
\hline History of CAD & $4(4.0)$ & $1(5.9)$ & 0.764 \\
\hline Diabetes mellitus & $12(12.1)$ & $3(17.6)$ & 0.813 \\
\hline \multicolumn{4}{|l|}{ Preoperative laboratory test } \\
\hline AST (IU/L) & $23.0(20.0-28.0)$ & $25.0(20.5-34.0)$ & 0.296 \\
\hline $\operatorname{ALT}(I U / L)$ & $22.0(18.0-29.0)$ & $21.0(19.0-38.0)$ & 0.550 \\
\hline Albumin (g/dL) & $4.6(4.3-4.7)$ & $4.4(4.3-4.6)$ & 0.094 \\
\hline Surgery time (min) & $37.0(25.0-56.0)$ & $30.0(25.0-53.5)$ & 0.734 \\
\hline PACU stay (min) & $62.0(53.0-74.0)$ & $57.0(50.0-93.0)$ & 0.896 \\
\hline Hospital stay (days) & $6.0(4.0-8.0)$ & $6.0(5.0-9.5)$ & 0.195 \\
\hline $\begin{array}{l}\text { Time to hemodynamic instability after initiating DMED } \\
\text { administration (min) }\end{array}$ & N/A & $67.0(37.4-96.6)$ & N/A \\
\hline
\end{tabular}

Continuous variables are presented as mean (SD) or median (interquartile range). Categorical variables are presented as number (\%)

Underweight $<18.5 \mathrm{~kg} / \mathrm{m}^{2}$; normal weight $18.5-24.9 \mathrm{~kg} / \mathrm{m}^{2}$; overweight $25.0-29.9 \mathrm{~kg} / \mathrm{m}^{2}$; obesity $\geq 30.0 \mathrm{~kg} / \mathrm{m}^{2}$

$B M I$ body mass index, CAD coronary artery disease, $A S T$ aspartate aminotransferase, $A L T$ alanine animotransferase, $P A C U$ postanesthesia care unit, $D M E D$ dexmedetomidine, $N / A$ not applicable

${ }^{*} P<0.05$ by chi-square test

${ }^{\dagger} P<0.05$ by Mann-Whitney rank-sum test 
Table 2 Dexmedetomidine therapy characteristics

\begin{tabular}{llll}
\hline & $\begin{array}{l}\text { Stable group } \\
(\boldsymbol{n = 9 9 )}\end{array}$ & $\begin{array}{l}\text { Unstable group } \\
(\boldsymbol{n = 1 7 )}\end{array}$ & $\boldsymbol{P}$ value \\
\hline Total consumption of DMED $(\boldsymbol{\mu g})$ & $78.1(65.6-89.0)$ & $78.4(62.5-91.6)$ & 0.746 \\
Total infusion time of DMED $(\mathrm{min})$ & $40.0(28.0-60.0)$ & $40.0(20.0-56.5)$ & 0.673 \\
Total consumption per b.w. $(\boldsymbol{\mu} \mathrm{g} / \mathrm{kg})$ & $1.2(1.1-1.3)$ & $1.2(1.1-1.3)$ & 0.894 \\
Concomitantly administered sedatives [n (\%)] & & $5(29.4)$ & 0.204 \\
$\quad$ Benzodiazepine & $49(49.5)$ & $1(5.9)$ & 0.824 \\
$\quad$ Fentanyl & $11(11.1)$ & & \\
\hline
\end{tabular}

Continuous variables are presented as median (interquartile range), and categorical variables are presented as number (\%)

DMED dexmedetomidine, b.w. body weight

DMED-induced transient hypertension was observed in 6 of the 116 patients (5.2\%), and all patients were allocated in the stable group. Among them, two had a history of concomitant hypertension and diabetes mellitus, two had a history of diabetes mellitus for over ten years, and one had a history of hypertension. The transient hypertension in all six patients was well controlled within a few minutes with intravenous anti-hypertensive drugs, without any significant complications.

The changes in SBP and heart rate following DMED administration are presented in Fig. 2. Within the stable group, there was no difference in the parameters over time. Meanwhile, within the unstable group, the SBP tended to decrease continuously over time, and it did not recover to baseline until the patients were discharged from the PACU. When compared to baseline, the SBP was significantly lower at $30 \mathrm{~min}$ after DMED infusion $(P=0.013)$, when infusion was discontinued $(P=0.014)$, at admission to the PACU $(P<0.001)$, at 10 , 20, 30, and 40 min after PACU admission $(P<0.001$ for all), and on discharge from PACU $(P<0.001)$, by the two-way RM ANOVA. In the unstable group, the SBP

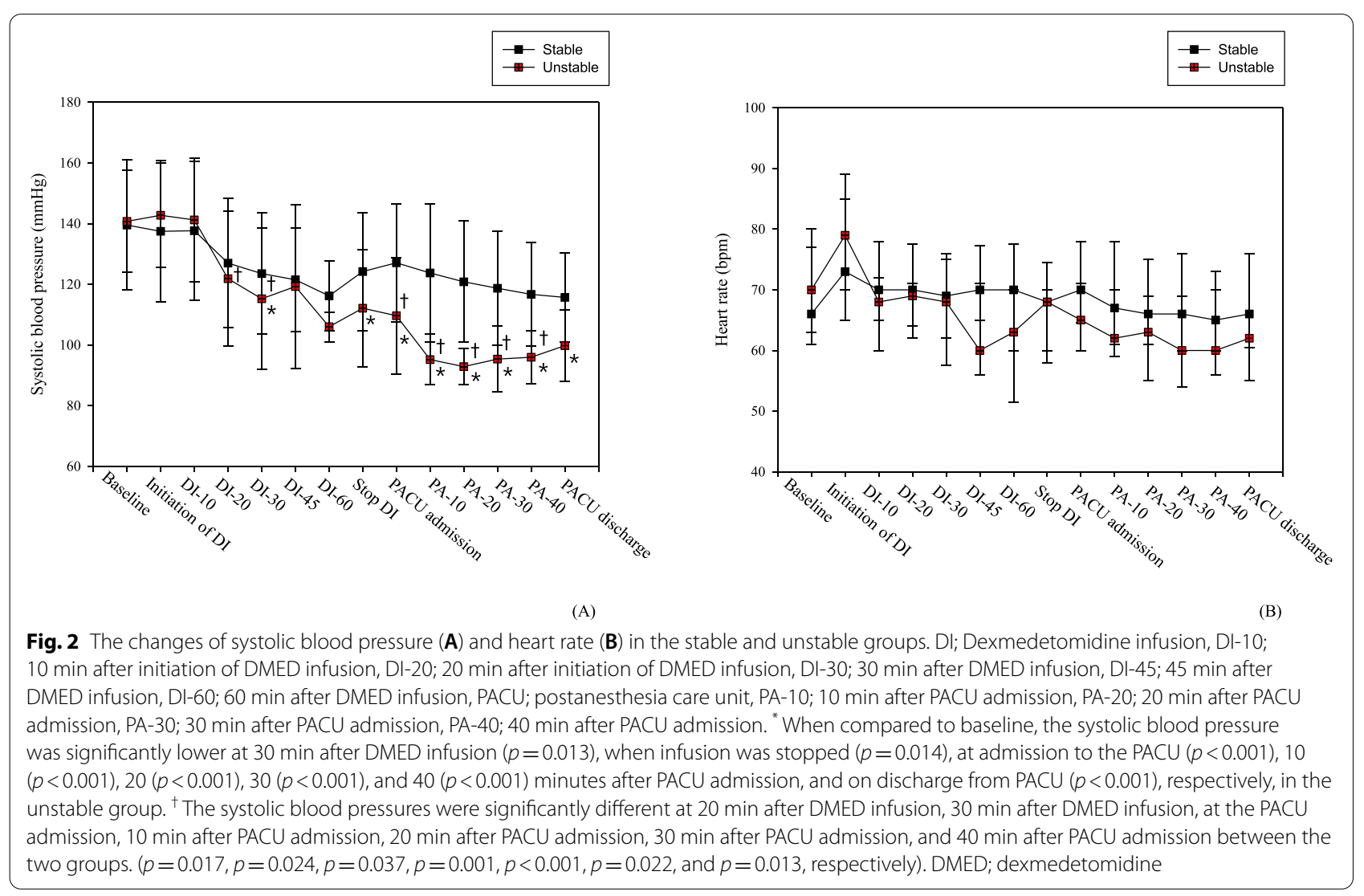


had maximally decreased by $32.9 \%$ below the baseline at 20 min after PACU admission. Between the two group, the SBP was significantly different at $20(P=0.017)$ and $30(P=0.024)$ minutes after the start of DMED infusion, at the PACU admission $(P=0.037)$, and at $10(P=0.001)$, $20(P<0.001), 30(P=0.022)$, and $40(P=0.013)$ minutes after PACU admission. There was no difference in the heart rate, both within and between the groups.

The univariate analysis revealed that sex (female), obesity $\left(B M I \geq 30 \mathrm{~kg} / \mathrm{m}^{2}\right)$, and pre-existing hypertension were significant predictors of DMED-induced hemodynamic instability (Table 3 ). In the multivariate analysis, both female sex (adjusted OR: 3.86, 95\% CI: 1.09-13.59, $P=0.036$ ) and obesity (adjusted OR: 6.41, 95\% CI: $1.22-$ $33.57, P=0.028$ ) were found to be independent predictors of DMED-induced hemodynamic instability.

We performed additional analysis, using the survival curve, followed by log-rank test and post-hoc analysis, with stratified patients' groups according to the sex and BMI (Fig. 3). The cumulative incidence of DMEDinduced hemodynamic instability was higher in females than in males $(P=0.004)$. When the analysis was done after stratifying the patients by BMI, the cumulative incidence of DMED-induced hemodynamic instability was significantly higher in obese patients than in normalweight or overweight patients $(P=0.001$ and $P=0.044$, respectively).

\section{Discussions}

The current study characterizes hemodynamic instability in patients sedated with DMED during surgery under regional anesthesia. Even though the hemodynamic effects of DMED, including hypotension and bradycardia, are well known [5, 12-14], there have been few related clinical practice investigations. In the current study, the prevalence of DMED-induced hemodynamic instability in regional anesthesia practice was found to be $14.7 \%$, and the event occurred at a median time of 67.0 (IQR

Table 3 Risk factors for dexmedetomidine-induced hemodynamic instability by logistic regression analysis

\begin{tabular}{|c|c|c|c|c|}
\hline & \multicolumn{2}{|l|}{ Univariate analysis } & \multicolumn{2}{|l|}{ Multivariate analysis } \\
\hline & Crude OR (95\% Cl) & $P$ value & Adjusted OR (95\% Cl) & $P$ value \\
\hline Female sex & $5.00(1.52-16.45)$ & $0.008^{*}$ & $3.86(1.09-13.59)$ & $0.036^{*}$ \\
\hline Obesity & $7.31(1.63-32.82)$ & $0.009^{*}$ & $6.41(1.22-33.57)$ & $0.028^{*}$ \\
\hline Concomitant HTN & $3.51(1.20-10.25)$ & $0.022^{*}$ & $2.37(0.73-7.71)$ & 0.152 \\
\hline
\end{tabular}

OR Odds ratio, $\mathrm{Cl}$ confidence interval

Obesity corresponds to body mass index $\geq 30 \mathrm{~kg} / \mathrm{m}^{2}$

HTN hypertension

${ }^{*} P<0.05$ was considered statistically significant
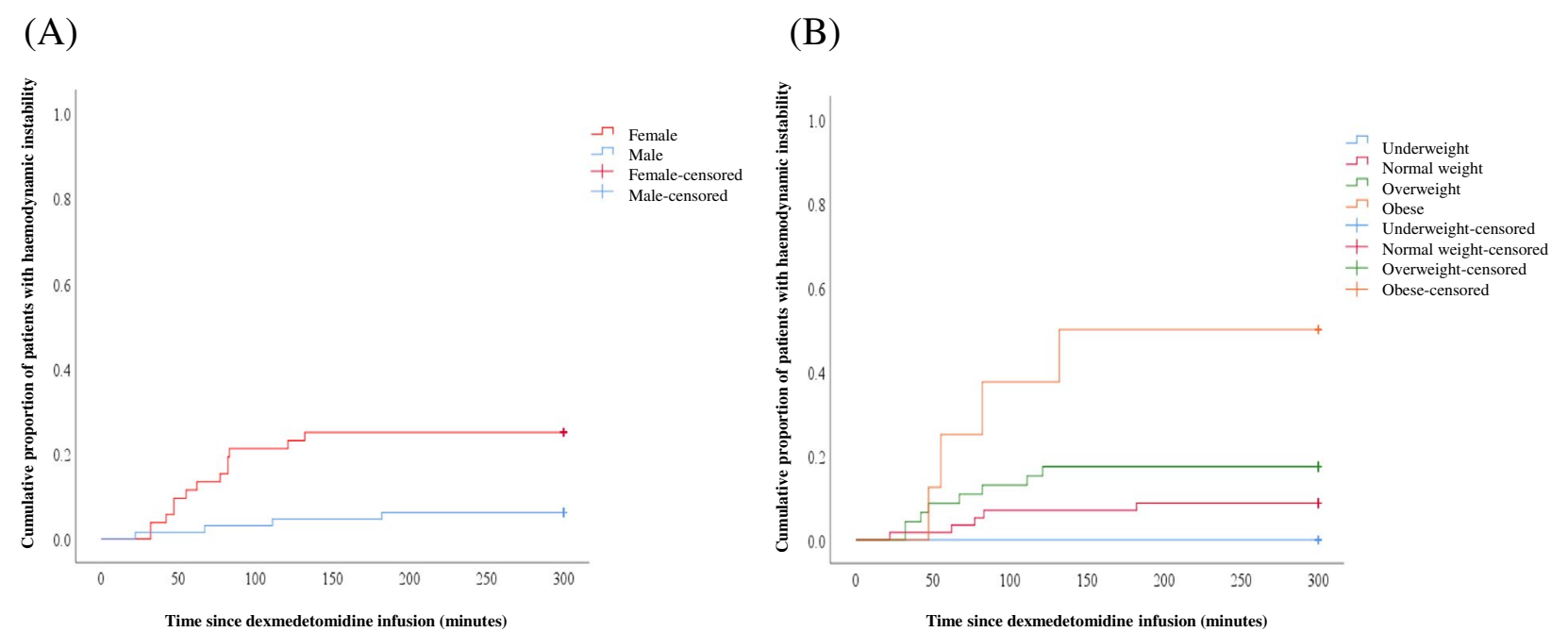

Fig. 3 Cumulative incidence of dexmedetomidine-induced hemodynamic instability in females and males $(\mathbf{A})$ and in stratified groups according to body mass index (B) 
37.4-96.6) minutes after initiating DMED administration. Similar results were reported in a study that followed-up patients for six hours. It was found that DMED induced a maximal decrease in blood pressure at $60 \mathrm{~min}$ after administration of a loading dose [5]. Remarkably, most patients (16/17) in the unstable group in our study experienced the hemodynamic instability during their stay at the PACU, regardless of the infusion time of DMED. Only one patient experienced hypotension during surgery while receiving DMED. The authors think that the release of vasodilating substances which had been accumulated in the surgical arm with pneumatic tourniquet might affect the development of hypotensive event not during the surgery but after the surgery. Moreover, the hypotensive effect of DMED in the unstable group was sustained until discharge from the PACU. This phenomenon suggests that patients administered DMED during surgical procedures should be monitored closely not only during the surgery but also during the recovery phase.

The hemodynamic change following DMED infusion, which was found to be dose-dependent and typically biphasic, is characterized by transient hypertension and reflex bradycardia, followed by hypotension $[4,5]$. At the initial loading phase, as the plasma level of DMED abruptly increases, hypertension and reflex bradycardia often occur as a result of peripheral vasoconstriction through postsynaptic $\alpha 2$-adrenoreceptor activation in the vascular smooth muscles. After the initial loading, when the plasma concentration of DMED decreases, activation of the postsynaptic $\alpha 2$-adrenoreceptors in the vascular endothelial cells causes peripheral vasodilatation. Simultaneously, activation of the presynaptic $\alpha 2$-adrenoreceptors also contributes to inducing hypotension during this phase [12-14]. Transient hypertensive episode following DMED loading can be eliminated by decreasing the loading dose or elongating the time to peak plasma concentration $[5,15]$. In the current study, only six patients in the stable group presented a significant hypertensive episode after infusion of $1 \mu \mathrm{g} / \mathrm{kg}$ of DMED over ten minutes. Among them, two had a history of concomitant hypertension and diabetes mellitus, two had a history of diabetes mellitus for over ten years, and one had a history of hypertension. Possible predictors for a hypertensive episode following DMED loading and a new dosing scheme for susceptible populations would be investigated in future studies.

Ice et al. [9] suggested that older age was an independent risk factor for DMED-induced hemodynamic instability in ICU patients, despite the influence of age on DMED pharmacokinetics not being conclusively proven $[16,17]$. The current study expanded the potential risk factors to include sex and BMI. Female sex and obesity were found to be independent risk factors for DMED-induced hemodynamic instability, while older age ( $>65$ years) did not affect it. Because obese patients generally have more fat tissue, the proportion of the lean body tissue to the total body weight is lower in this population. In addition, the blood flow is distributed mainly to the vessel-rich or lean body tissues (brain, muscle, heart, etc.), as fat tissue is normally poorly perfused. Consequently, dosing based on total body weight is prone to overdose obese patients and results in a higher peak plasma concentration of the drug than lean subjects [18, 19]. DMED, a highly lipophilic drug, has a large volume of distribution. It can rapidly distribute to fatty tissues and pass the blood-brain barrier into the brain [4]. It is wellknown that the distribution of the lipophilic drugs to fat or lean body tissues could alter their pharmacokinetics. In several studies investigating the pharmacokinetics of DMED in obese patients, peak plasma concentration was significantly higher in obese patients, even with a higher volume of distribution, than observed in normal-weight patients when dosed by total body weight [19-21]. Based on the current study's results, these pharmacokinetic differences might contribute to the more pronounced hypotension and other cardiovascular effects of DMED in obese patients. Even though females generally have a higher proportion of fat tissue to total body weight, the precise mechanisms explaining why the DMED-induced hemodynamic instability develops more often in females should be investigated in future.

The study has some limitations. First, inter-individual variability was not controlled in the study. Hypoalbuminemia and lower cardiac output were suggested to induce prolonged DMED effects in critically ill patients [17]. DMED has a high protein binding capability, with $94 \%$ of it bound to albumin and $\alpha 1$-glycoprotein. Hypoalbuminemia can thus be expected to affect the drug's pharmacokinetics [4, 17]. However, all enrolled participants in the current study were healthy patients with ASA/PS I-III. Subjects in critical medical conditions were excluded from the study. Furthermore, several factors that might induce inter-individual variabilities, such as ethnicity and genetic polymorphism, have been suggested [21]. Yet, there are no clinical recommendations to guide dosing regimens by population type. Second, indirect measurement of blood pressure in the current study might be prone to error in identifying the DMEDinduced hemodynamic instability. Third, we did not investigate whether the DMED-induced hemodynamic instability could negatively affect perioperative outcomes. Mathis MR et al. has shown that hypotension did not increase the risk of postoperative organ injury in patients with low risk [22]. The clinical significance of short and long-term perioperative cardiovascular or neurologic 
outcomes even in high risk patients will be clarified in future studies. Finally, this study is limited due to the retrospective design and the small number of participants. Further investigation in a larger study population would be needed.

\section{Conclusions}

In conclusion, this retrospective cohort study found a prevalence of DMED-induced hemodynamic instability of $14.7 \%$ in patients administered with intravenous DMED at a loading dose of $1 \mu \mathrm{g} / \mathrm{kg}$, followed by $0.2-$ $0.6 \mu \mathrm{g} / \mathrm{kg} / \mathrm{hr}$ for sedation during orthopedic upper limb surgery under BPB. Female sex and obesity were found to be associated with a higher probability of developing DMED-induced hemodynamic instability. These findings suggest that the administered dose of DMED may be diminished to prevent hypotensive risk in female and obese patients.

\begin{abstract}
Abbreviations
DMED: Dexmedetomidine; ICU: Intensive care unit; BPB: Brachial plexus block; ASA PS: American Society of Anesthesiologist Physical Status; BMI: Body mass index; PACU: Postanesthesia care unit; SBP: Systolic blood pressure; RM ANOVA: Repeated measures analysis of variance; OR: Odds ratio; Cl: Confidence interval.

\section{Acknowledgements}

Not applicable.

\section{Authors' contributions}

A.R.D. helped perform the research and wrote the original draft. H.S.L. helped collect data and perform statistical analysis. S.J.B. helped collect data. J.W.L. helped design the research and edit and revise the manuscript. All authors reviewed the final manuscript. The authors read and approved the final manuscript.
\end{abstract}

\section{Funding}

This paper was supported by Fund of Biomedical Research Institute, Jeonbuk National University Hospital.

\section{Availability of data and materials}

The data analyzed during the current study are available from the corresponding author on reasonable request.

\section{Declarations}

\section{Ethics approval and consent to participate}

The study was performed in accordance with the Good Clinical Practice regulations and guidelines and in conformity with the ethical principles of the Declaration of Helsinki. Institutional Review Board of Jeonbuk National University Hospital approved the study (IRB number; CUH 2019-11-025-001) and waived the requirement to obtain informed consent based on the Good Clinical Practice regulations and guidelines.

\section{Consent for publication}

Not applicable.

\section{Competing interests}

The authors report no potential conflict of interest in this work.

\section{Author details}

${ }^{1}$ Department of Anesthesiology and Pain Medicine, Jeonbuk National University Hospital and Medical School, 20 Geonji-ro, Deokjin-gu, Jeonju 54907,
Jeollabuk-do, South Korea. ${ }^{2}$ Research Institute of Clinical Medicine of Jeonbuk National University-Biomedical Research Institute of Jeonbuk National University Hospital, Jeonju, South Korea.

Received: 8 March 2021 Accepted: 14 June 2021

Published online: 16 September 2021

\section{References}

1. Vorobeichik L, Brull R, Abdallah FW. Evidence basis for using perineural dexmedetomidine to enhance the quality of brachial plexus nerve blocks: a systematic review and meta-analysis of randomized controlled trials. Br J Anesth. 2017;118:167-81.

2. Prabhakar A, Lambert T, Kaye RJ, Gaignard SM, Ragusa J, Wheat S, et al. Adjuvants in clinical regional anesthesia practice: A comprehensive review. Best Pract Res Clin Anesthesiol. 2019;33:415-23.

3. Ahuja V, Thapa D, Chander A, Gombar S, Gupta R, Gupta S. Role of dexmedetomidine as adjuvant in postoperative sciatic popliteal and adductor canal analgesia in trauma patients: a randomized controlled trial. Korean J Pain. 2020;33:166-75.

4. Weerink MAS, Struys M, Hannivoort LN, Barends CRM, Absalom AR, Colin P. Clinical Pharmacokinetics and Pharmacodynamics of Dexmedetomidine. Clin Pharmacokinet. 2017;56:893-913.

5. Bloor BC, Ward DS, Belleville JP, Maze M. Effects of intravenous dexmedetomidine in humans. II. Hemodynamic changes. Anesthesiology. 1992;77:1134-42.

6. Frölich MA, Arabshahi A, Katholi C, Prasain J, Barnes S. Hemodynamic characteristics of midazolam, propofol, and dexmedetomidine in healthy volunteers. J Clin Anesth. 2011;23:218-23.

7. Jakob SM, Ruokonen E, Grounds RM, Sarapohja T, Garratt C, Pocock SJ, et al. Dexmedetomidine vs midazolam or propofol for sedation during prolonged mechanical ventilation: two randomized controlled trials. JAMA. 2012;307:1151-60.

8. Riker RR, Shehabi Y, Bokesch PM, Ceraso D, Wisemandle W, Koura F, et al. Dexmedetomidine vs midazolam for sedation of critically ill patients: a randomized trial. JAMA. 2009;301:489-99.

9. Ice CJ, Personett HA, Frazee EN, Dierkhising RA, Kashyap R, Oeckler RA. Risk Factors for Dexmedetomidine-Associated Hemodynamic Instability in Noncardiac Intensive Care Unit Patients. Anesth Analg. 2016;122:462-9.

10. Gerlach AT, Dasta JF, Steinberg S, Martin LC, Cook CH. A new dosing protocol reduces dexmedetomidine-associated hypotension in critically ill surgical patients. J Crit Care. 2009;24:568-74.

11. Tran DQ, Dugani S, Correa JA, Dyachenko A, Alsenosy N, Finlayson RJ. Minimum effective volume of lidocaine for ultrasound-guided supraclavicular block. Reg Anesth Pain Med. 2011;36:466-9.

12. Talke P, Lobo E, Brown R. Systemically administered alpha2-agonistinduced peripheral vasoconstriction in humans. Anesthesiology. 2003;99:65-70.

13. Nong L, Ma J, Zhang G, Deng C, Mao S, Li H, et al. Dexmedetomidine inhibits vasoconstriction via activation of endothelial nitric oxide synthase. Korean J Physiol Pharmacol. 2016;20:441-7.

14. Seyrek M, Halici Z, Yildiz O, Ulusoy HB. Interaction between dexmedetomidine and alpha-adrenergic receptors: emphasis on vascular actions. J Cardiothorac Vasc Anesth. 2011;25:856-62.

15. Dyck JB, Maze M, Haack C, Vuorilehto L, Shafer SL. The pharmacokinetics and hemodynamic effects of intravenous and intramuscular dexmedetomidine hydrochloride in adult human volunteers. Anesthesiology. 1993;78:813-20.

16. De Wolf AM, Fragen RJ, Avram MJ, Fitzgerald PC, Rahimi-Danesh F. The pharmacokinetics of dexmedetomidine in volunteers with severe renal impairment. Anesth Analg. 2001;93:1205-9.

17. Iirola T, Ihmsen H, Laitio R, Kentala E, Aantaa R, Kurvinen JP, et al. Population pharmacokinetics of dexmedetomidine during long-term sedation in intensive care patients. Br J Anesth. 2012;108:460-8.

18. Cheymol G. Effects of obesity on pharmacokinetics implications for drug therapy. Clin Pharmacokinet. 2000;39:215-31.

19. Cortinez LI, Anderson BJ, Holford NH, Puga V, de la Fuente $\mathrm{N}$, Auad H, et al. Dexmedetomidine pharmacokinetics in the obese. Eur J Clin Pharmacol. 2015;71:1501-8. 
20. Xu B, Zhou D, Ren L, Shulman S, Zhang X, Xiong M. Pharmacokinetic and pharmacodynamics of intravenous dexmedetomidine in morbidly obese patients undergoing laparoscopic surgery. J Anesth. 2017;31:813-20.

21. Lee S, Kim BH, Lim K, Stalker D, Wisemandle W, Shin SG, et al. Pharmacokinetics and pharmacodynamics of intravenous dexmedetomidine in healthy Korean subjects. J Clin Pharm Ther. 2012;37:698-703.

22. Mathis MR, Naik BI, Freundlich RE, Shanks AM, Heung M, Kim M, et al. Preoperative Risk and the Association between Hypotension and Postoperative Acute Kidney Injury. Anesthesiology. 2020;132:461-75.

\section{Publisher's Note}

Springer Nature remains neutral with regard to jurisdictional claims in published maps and institutional affiliations.
Ready to submit your research? Choose BMC and benefit from:

- fast, convenient online submission

- thorough peer review by experienced researchers in your field

- rapid publication on acceptance

- support for research data, including large and complex data types

- gold Open Access which fosters wider collaboration and increased citations

- maximum visibility for your research: over 100M website views per year

At BMC, research is always in progress.

Learn more biomedcentral.com/submissions 